\title{
ВЛИЯНИЕ ЛИЗИНГА НА КОНКУРЕНТОСПОСОБНОСТЬ РЕГИОНА
}

\author{
(c) 2019 Фатхуллин Альберт Рашитович \\ ассистент кафедры управления человеческими ресурсами \\ Казанский (Приволжский) федеральный университет, Россия, Казань \\ E-mail: 2361646@mail.ru
}

Лизинг является современным инструментом, позволяющим модернизировать основные средства предприятия и обеспечивать его конкурентоспособность. В статье проанализировано влияние лизинга на конкурентоспособность региона. Предложен механизм определения значимости факторов конкурентоспособности региона.

Ключевые слова: конкурентоспособность региона, лизинг машин, лизинг оборудования, лизинг транспорта, финансовый лизинг, инвестиции.

В последние годы в России сфера деятельности лизинговых компаний расширяется за счет новых отраслей и видов имущества, увеличиваются сроки лизинговых договоров, финансовые условия становятся более выгодными для лизингополучателей. Лизинговые схемы заняли важное место в реализации приоритетных национальных проектов, прежде всего в сельском хозяйстве. Все это позволяет говорить о том, что роль механизмов лизинга в российской экономике постепенно возрастает.

По результатам исследования, проведенного Эксперт РА лизинговый рынок, как один из индикаторов инвестиционной активности в экономике, показал положительную динамику. Увеличение объема нового бизнеса (стоимости имущества) за 2018 год составило около $20 \%$ (рисунок 1).

Крупнейшим сегментом рынка остается ав- толизинг (совокупно легковой и грузовой автотранспорт), который составляет более 30\% в 2018 г., железнодорожная техника уступает незначительно - 25,9\%, в общем портфеле - 41\%, на третьем месте лизинг авиационного транспорта - 12,6\%, который занимает наибольшую долю в лизинговом портфеле - 21,3\%. Остальные предметы лизинга занимают долю в новом бизнесе меньшую, чем $10 \%$.

Наибольшее развитие в 2018 г. получили договора лизинга на приобретение автотранспорта. Железнодорожная и авиатехника в 2018 г. занимает существенную долю в объеме лизингового портфеля.

Количество лизинговых сделок в 2018 году составило не менее 230 тыс. (-20\% к 2017 году). Средняя сумма сделки на рынке за 2018 год составила 9,1 млн. руб.

Данные показатели свидетельствуют об ак-

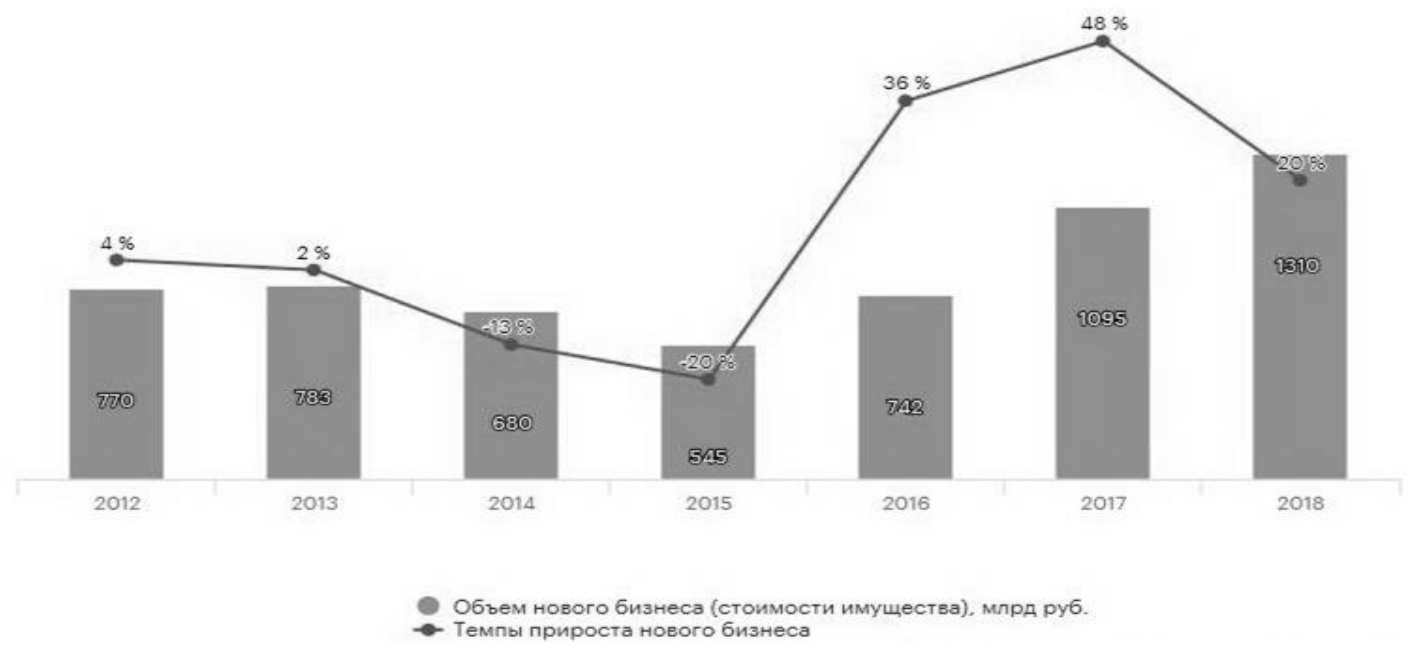

Puc. 1. Динамика объема нового бизнеса [1] 
тивном росте рынка лизинговых услуг. Предприятия активно использовали в 2018 г. в рамках своих финансовых стратегий привлечение денежных средств посредством лизинга.

Географическое распределение новых договоров лизинга за 2017-2018 годы представлено на рисунке 2.

Приволжский ФО в 2018г показал незначительный рост новых договоров лизинга с 9,2\% до 9,3\%, однако темпы прироста были ниже чем у лидеров рейтинга, что свидетельствует о необходимости поиска новых заказчиков и предоставление клиентоориентированных услуг.

В статье мы анализируем влияние лизинга и инвестиций на конкурентоспособность региона.

Рейтинг конкурентоспособности регионов включает в себя множество показателей, однако не вполне понятно насколько конкретный вид инвестиции оказывает влияние на позицию региона в рейтинге [2]. Мы выбрали ряд показателей, которые могут оказывать влияние на конкурентоспособность региона, присутствуют показатели из разных элементов структуры данного рейтинга: рынки, природные ресурсы, человеческий капитал, инновации и информация, институты, инвестиции. Таким образом, в качестве определяющих переменных взяты:

1) лизинг основных фондов (lizingof);

2) лизинг зданий;

3) лизинг машин и оборудования (lizing mach);

4) лизинг транспорта;

5) лизинг компьютеров и компьютерной техники;
6) инвестиции в основной капитал (invok); инвестиции в модернизацию (invmod);

7) число абонентских устройств подвижной радиотелефонной (сотовой) связи (sot);

8) ВПР на душу населения (vrp/dusha);

9) продукция сельского хозяйства (prodselhoz);

10) зарегистрировано заболеваний у пациентов с диагнозом, установленным впервые в жизни, на 1000 человек населения (zabolev/10000).

В качестве определяемой переменной взята конкурентоспособность региона. Поскольку отсутствует ряд показателей по некоторым регионам, часть из них была исключена: Калужская область, Республика Карелия, Республика Коми, Республика Крым, Астраханская область, Кабардино-Балкарская Республика, Республика Северная Осетия - Алания, Чеченская Республика, Республика Ингушетия, Тюменская область, Ханты-Мансийский автономный округ-Югра, Ямало-Ненецкий автономный округ, Тюменская область (без автономных округов), Республика Тыва, Амурская область, Магаданская область, Еврейская АО, Чукотский автономный округ.

Таким образом, осталось 70 регионов, период рассмотрения -4 года, поскольку данные рейтинга конкурентоспособности представлены за 2013-2016 гг. В качестве факторов модели мы оставили: лизинг основных фондов, лизинг машин и оборудования, инвестиции в основной капитал, инвестиции в модернизацию, ВРП на душу населения, числом абонентских устройств подвижной радиотелефонной (сотовой) связи,

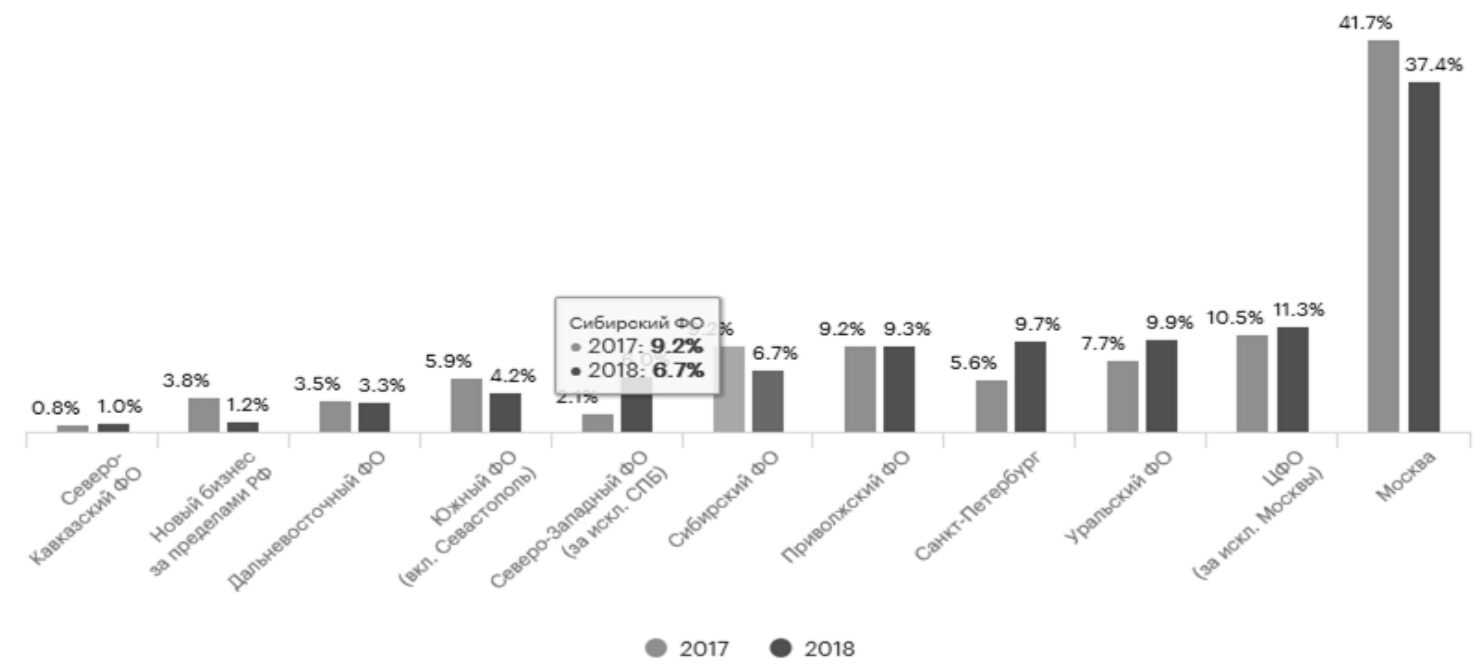

Puc. 2. Распределение новых договоров лизинга в разрезе федеральных округов 2017-2018 годы [1] 
продукцию сельского хозяйства, зарегистрировано заболеваний у пациентов с диагнозом, установленным впервые в жизни, на 1000 человек населения.

Нами была проведена проверка факторов на мультиколлинеарность. В связи с внутренней зависимостью между объясняющими переменными, приводящей к искажению уровня их влияния на результат. Результаты проверки представлены в таблице 1.

По принятой классификации влияния слабая связь переменных присутствует при значении $[0 ; 0,3)$ и средне $[0,3 ; 0,7)$. В нашем случае переменные коррелируют слабо и средне, что не ведет к смещению оцениваемых параметров. Однако, в случае лизинга основных фондов и лизинга машин и оборудования наблюдается сильная связь, что создает необходимость исключить один из параметров. С конкурентоспособностью в большей взаимосвязи находится лизинг машин и оборудования, чем лизинг основных фондов. Причем конкурентоспособность оказалась в средней связи с числом абонентских устройств подвижной радиотелефонной (сотовой) связи 0,47; ВРП на душу населения - 0,37; лизингом машин и оборудования - 0,48. Данные показывают, что не все показатели, которые используются при расчете конкурентоспособности имеют сколько-нибудь значимое влияние на конкурентоспособность, в то время как показатель не используемый в модели - лизинг машин и оборудования показывает большую взаимосвязь с объясняемой переменной. Данный факт может свидетельствовать о том, что рейтинг конкурентоспособности не в полной мере отражает реальное положение региона на рынке. Кроме того, лизинг машин и оборудования имеет взаимосвязь с ВРП на душу населения и с числом абонентских устройств подвижной радиотелефонной (сотовой) связи.

Кроме того, мы рассчитали корреляцию по годам между конкурентоспособностью и объясняемыми переменными. Данные представлены в таблице 2 .

Таким образом, значимость факторов модели можно представить следующим образом (таблица 3)

Если рассматривать поведение факторов во времени, то можно выделить три фактора, которые оказывают прямое средне влияние на конкурентоспособность региона: лизинг машин и оборудования, число абонентских устройств подвижной радиотелефонной (сотовой) связи, ВРП на душу населения. Продукция сельского хозяйства оказалась значимым фактором только в 2015 г. Остальные факторы показали слабую взаимосвязь с объясняемой переменной.

Используя, программу Stata 8, мы построили

Таблица 1. Результаты проверки факторов на мультиколлинеарность за 2016 г. [3]

\begin{tabular}{|l|c|c|c|c|c|c|c|c|c|}
\hline & KONK & lizingof & $\begin{array}{c}\text { lizing } \\
\text { mach }\end{array}$ & invok & invmod & $\begin{array}{c}\text { vrp/ } \\
\text { dusha }\end{array}$ & $\begin{array}{c}\text { zabolev/ } \\
10000\end{array}$ & $\begin{array}{c}\text { sot } \\
\text { selhoz }\end{array}$ \\
\hline KONK & 1.000 & & & & & & & & \\
\hline lizingof & 0.449 & 1.000 & & & & & & & \\
\hline lizing mach & 0.485 & 0.985 & 1.000 & & & & & & \\
\hline invok & 0.020 & 0.069 & 0.063 & 1.000 & & & & & \\
\hline invmod & -0.119 & -0.033 & -0.039 & -0.117 & 1.000 & & & & \\
\hline vrp/dusha & 0.371 & 0.460 & 0.469 & -0.086 & -0.228 & 1.000 & & & \\
\hline zabolev/10000 & -0.066 & -0.119 & -0.105 & -0.095 & -0.002 & 0.141 & 1.000 & & \\
\hline sot & 0.471 & 0.410 & 0.435 & -0.140 & 0.133 & 0.474 & 0.150 & 1.000 & \\
\hline prodselhoz & 0.237 & -0.094 & -0.102 & 0.322 & -0.096 & -0.088 & -0.187 & 0.022 & 1.000 \\
\hline
\end{tabular}

Таблица 2. Корреляция факторов с показателем конкурентоспособности региона [3]

\begin{tabular}{|c|c|c|c|c|c|c|c|}
\hline & lizing mach & invok & invmod & vrp/dusha & zabolev/10000 & sot & prodselhoz \\
\hline 2013 & 0.49 & 0.02 & -0.12 & 0.37 & -0.07 & 0.47 & 0.24 \\
\hline 2014 & 0.49 & -0.15 & -0.14 & 0.32 & -0.11 & 0.43 & 0.27 \\
\hline 2015 & 0.50 & 0.25 & 0.09 & 0.33 & -0.12 & 0.41 & 0.30 \\
\hline 2016 & 0.50 & 0.06 & -0.03 & 0.34 & -0.11 & 0.44 & 0.29 \\
\hline
\end{tabular}


Таблица 3. Общая характеристика факторов [3]

\begin{tabular}{|c|c|c|c|c|c|c|c|}
\hline & lizing mach & invok & invmod & vrp/dusha & zabolev/10000 & sot & prodselhoz \\
\hline 2013 & + & не значим & не значим & + & не значим & + & не значим \\
\hline 2014 & + & не значим & не значим & + & не значим & + & не значим \\
\hline 2015 & + & не значим & не значим & + & не значим & + & + \\
\hline 2016 & + & не значим & не значим & + & не значим & + & не значим \\
\hline
\end{tabular}

модель структурной устойчивости конкурентоспособности региона за 2016 г. Результаты модели представлены в таблице 4.

По результатам модели видно, что значимыми факторами модели стали: продукция сельского хозяйства, лизинг машин и число абонентских устройств подвижной радиотелефонной (сотовой) связи. Модель статистически значима и может быть использована для прогнозирования. Коэффициент детерминации модели равен 0,5 . Максимальный и минимальный показатель значимых переменных не меняет знак.

Затем, мы построили динамическую модель, для того, чтобы оценить поведение переменных во времени. В общем виде регрессионная динамическая модель панельных данных с фиксированными эффектами имеет следующий вид:

xit $=$ Zit $\alpha+$ fi + eit,

где предполагается, что Zit - независимы от cit для всех і и t. Ошибки вit - независимые одинаково распределённые случайные величины, $\mathrm{E}(\varepsilon \mathrm{it})=0, \mathrm{E}(\varepsilon 2 \mathrm{it})=\sigma 2 \varepsilon$ для всех і и t. [4]

$\mathrm{x}_{i t}-$ анализируемый параметр конкурентоспособности регионов,

Динамическая модель конкурентоспособности регионов оценки панельных данных представлена в таблице 5.

Динамическая модель показала значимость тех же параметров, что и модель структурной устойчивости, данный факт говорит об устойчивости поведения модели во времени. Значимыми факторами стали: продукция сельского хозяйства, лизинг машин и число абонентских устройств подвижной радиотелефонной (сотовой) связи. Большую значимость в динамической модели показывает ВРП на душу населения, чем в статической модели.

Обеспеченность региона продукцией сель-

Таблица 4. Модель структурной устойчивости поведения конкурентоспособности регионов в 2016 г. [3]

\begin{tabular}{|r|c|c|c|c|c|c|}
\hline \multicolumn{1}{|c|}{ knok } & Coef. & Std. Err. & $\mathrm{t}$ & $\mathrm{P}>|\mathrm{t}|$ & $\begin{array}{c}{[95 \% \text { Conf. }} \\
\text { Interval] }\end{array}$ & \\
\hline lizingmach & $3.00 \mathrm{e}-08$ & $9.74 \mathrm{e}-09$ & 3.09 & 0.003 & $1.06 \mathrm{e}-08$ & $4.95 \mathrm{e}-08$ \\
\hline prodselhoz & $6.80 \mathrm{e}-06$ & $1.74 \mathrm{e}-06$ & 3.91 & 0.000 & $3.32 \mathrm{e}-06$ & .0000103 \\
\hline invok & -.0002837 & .006514 & -0.04 & 0.966 & -.0135931 & .0130256 \\
\hline invmod & .0045352 & .0153246 & 0.30 & 0.768 & -.0261292 & 0.0351995 \\
\hline vrp & $7.98 \mathrm{e}-07$ & $5.80 \mathrm{e}-07$ & 1.38 & 0.174 & $-3.62 \mathrm{e}-07$ & $1.96 \mathrm{e}-06$ \\
\hline zabolev & -.0005593 & .0007832 & -0.71 & 0.478 & -.0021264 & .0010079 \\
\hline sot & .0008157 & .0002865 & 2.85 & 0.006 & .0002423 & .001389 \\
\hline cons & -.1589434 & .9208484 & -0.17 & 0.864 & -2.001557 & 1.68367 \\
\hline
\end{tabular}

Таблица 5. Динамическая модель конкурентоспособности регионов оценки панельных данных [3]

\begin{tabular}{|r|c|c|c|c|c|c|}
\hline \multicolumn{1}{|c|}{ knok } & Coef. & Std. Err. & $\mathrm{t}$ & $\mathrm{P}>|\mathrm{t}|$ & $\begin{array}{c}\text { [95\% Conf. } \\
\text { Interval] }\end{array}$ & \\
\hline lizingmach & $2.74 \mathrm{e}-08$ & $4.64 \mathrm{e}-09$ & 5.90 & 0.000 & $1.82 \mathrm{e}-08$ & $3.65 \mathrm{e}-08$ \\
\hline invok & -.0012409 & .0038158 & -0.33 & 0.745 & -.0087541 & .0062724 \\
\hline invmod & -.0007661 & .006436 & -0.12 & 0.905 & -.0134385 & .0119063 \\
\hline vrpdusha & $5.66 \mathrm{e}-07$ & $2.52 \mathrm{e}-07$ & 2.25 & 0.025 & $7.02 \mathrm{e}-08$ & $1.06 \mathrm{e}-06$ \\
\hline zabolev1000 & -.0002508 & .000354 & -0.71 & 0.479 & -.0009477 & .0004462 \\
\hline sot & .0009183 & .0001898 & 4.84 & 0.000 & .0005447 & .001292 \\
\hline prodselhoz & $6.76 \mathrm{e}-06$ & $9.27 \mathrm{e}-07$ & 7.29 & 0.000 & $4.94 \mathrm{e}-06$ & $8.59 \mathrm{e}-06$ \\
\hline _cons & -.1321223 & .5440472 & -0.24 & 0.808 & -1.203346 & .9391014 \\
\hline
\end{tabular}


ского хозяйства говорит о его продовольственной безопасности и возможности удовлетворения первичных потребностей населения, что оказывает влияние на конкурентоспособность данного субъекта.

Число абонентских устройств подвижной радиотелефонной (сотовой) связи отражает вовлеченность населения в процессах информатизации и степень включения региона в постиндустриальное развитие, кроме того, данный показатель косвенно свидетельствует об уровне жизни населения [5].

Лизинг машин и оборудования свидетельствует о производственном оснащении региона и о тенденции к замене данного оборудования, данный показатель в большей степени связан с конкурентоспособностью, чем, например, лизинг транспорта.

Регрессионная модель панельных данных с фиксированными эффектами получила следующий вид:

$K_{\text {KONK }}$ it $=0.684$ lizing mach $_{i t}+0.613$ sot $_{i t}+$ 0.455 prodselhoz $_{i t}+\phi_{i}+\varepsilon_{i t}$,

где $K O N K_{i t}-$ анализируемый параметр конкурентоспособности по регионам за 2016 г., prodselhoz $i t$ - продукция сельского хозяйства по регионам за 2016г, lizing mach $_{i t}-$ лизинг машин и оборудования по регионам за 2016г, $s o t_{i t}-$ число абонентских устройств подвижной радиотелефонной (сотовой) связи, $\phi_{i}-$ межрегиональная фиксированная ошибка (не зависит от времени), $\varepsilon_{i t}-$ случайная ошибка. $\mathrm{E}\left(\varepsilon_{i t}\right)=0$, var $\left(\varepsilon_{i t}\right)=\mathrm{r}^{2}$ для всех і и $\mathrm{t}$.

Таким образом, нами был предложен механизм определения факторов конкурентоспособности регионов

На основании выработанного механизма выявлены факторы, оказывающие наибольшее влияние на конкурентоспособность региона: лизинг машин, число абонентских устройств подвижной радиотелефонной, продукция сельского хозяйства по регионам. На основании полученных данных целесообразным является построение рейтинга конкурентоспособности регионов, включающего в себя данные факторы.

Полученный механизм показал, что значимыми факторами конкурентоспособности регионов являются: продукция сельского хозяйства, лизинг машин и число абонентских устройств подвижной радиотелефонной (сотовой) связи.

\section{Библиографический список}

1. Эксперт-PA RAEX (Эксперт PA), Рэнкинг лизинговых компаний. URL: http: raexpert.ru (обращения: 11.12.2019)

2. Аксенов И.А., Валеева Ю.С., Галимова Э.И., Демьянова О.В., Дюдина О.В., Жуков А.С., Захаров С.В., Казначевский Б.А., Макарова Е.С., Никифоров О.А., Нечитайлов А.С., Николаев М.В., Романова Т.Е., Саубанов К.Р., Сербиновский Б.Ю., Султанова Д.Ш., Тесленко И.Б., Тимошенко О.В., Ткач А.В., Фахрутдинова Е.В. и др. Факторы повышения конкурентоспособности региона/ Коллективная монография / Казань, 2018. Том 2

3. Составлено автором на основе данных Федеральной службы статистики с использованием программного пакета Stata8.

4. Суслов В.И., Лапо В.Ф., Талышева Л.П., Ибрагимов Н.М. Эонометрия-3. URL: http://files.lib.sfu-kras.ru/ebibl/ umkd/1367/u_lectures.pdf (дата обращения:26.06.2019)

5. олесникова Ю.С. Развитие нематериальной собственности в информационной экономике/диссертация на соискание ученой степени кандидата экономических наук / Казан. (Приволж.) федер. ун-т. Казань, 2012 - C.83-87.

6. Факторы повышения конкурентоспособности региона (том 1) /Колл.монография - Казань: Компания КноРус, 2018. - 300с.

7. Факторы повышения конкурентоспособности региона (том 2) /Колл.монография - Казань: Компания КноРус, 2018. - 238c. 